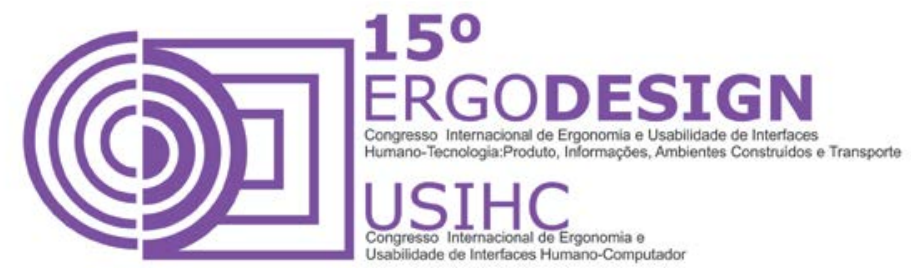

\title{
DESENVOLVIMENTO DO SISTEMA DE WAYFINDING PARA O CAMPUS DUNAS FANOR/DEVRY
}

\section{DEVELOPMENT OF THE WAYFINDING SYSTEM FOR CAMPUS DUNAS FANOR I DEVRY}

\author{
SILVA, Jackson Alves da (1); \\ ALVES, Maria Aurileide Ferreira (2) \\ (1) Faculdade Fanor/DeVry, Bacharel em Design \\ e-mail:jacksilver29@gmail.com \\ (2) Universidade Federal de Pernambuco - UFPE, Especialista ${ }^{1}$ \\ e-mail:aurileide@gmail.com
}

\begin{abstract}
RESUMO
O Campus Dunas da Fanor/DeVry, em Fortaleza-CE, apresenta problemas de orientação devido à sinalização atual. O presente trabalho propõe um novo sistema de sinalização para o ambiente, desenvolvido dentro dos princípios do design gráfico ambiental, que envolvem o design de produto, a arquitetura, o design gráfico e o paisagismo no campo da sinalização. Utilizando a metodologia de Wayfinding e da señalética como norteadores da pesquisa, o resultado final apresenta um conjunto de elementos para um novo sistema integrado à arquitetura do Campus e à identidade visual da instituição.

Palavras-chave: Sinalização. Design. Design gráfico-ambiental. Identidade Visual. Wayfinding.
\end{abstract}

\begin{abstract}
The Campus Dunas Fanor/DeVry, in Fortaleza, presents orientation problems due to the current signaling. This paper proposes a new sign system for the environment, developed within the principles of environmental graphic design, involving product design, architecture, graphic design and landscaping in the field of sign design. Using the Wayfinding and señalética methodology as guiding the research, the end result has a number of elements for a new integrated system to the architecture of the campus and the visual identity of the institution.
\end{abstract}

Keywords : Signage. Design. Environmental graphic design.Visual Identity.Wayfindings.

\footnotetext{
${ }^{1}$ Mestranda em Design da Informação no Programa de Pós-Graduação em Design da UFPE (2014-2016).
} 


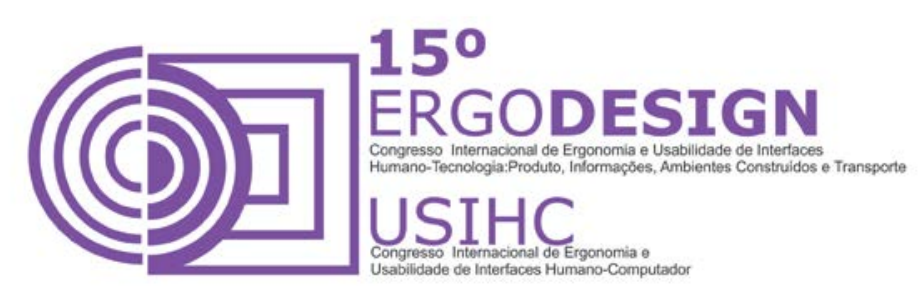

\section{INTRODUÇÃO}

Principal unidade universitária das Faculdades Norteste-Fanor/DeVry, em Fortaleza, o campus Dunas começou a ser utilizado em 2002 por locação e posteriormente aquisição do prédio onde antes funcionava o Colégio Geo Dunas. De lá para cá, o edifício passou e ainda passa por diversas reformas que ignoram a importância dos elementos de localalização e identificação de rotas dos usuários. Como consequência, a sinalização existente no campus não supre a demanda por informação causando transtornos aos frequentadores deste espaço.

Com base nessas dificuldades, após realizar vários estudos com os transeuntes e usuários regulares, o presente trabalho visa encontrar soluções para o seguinte problema: como a sinalização pode ajudar os frequentadores do campus Dunas em sua localização?

\section{OBJETIVOS}

Este trabalho trata do desenvolvimento do projeto de um novo sistema de sinalização para o campus Dunas da Fanor/DeVry, utilizando-se das informações coletadas dos usuários do ambiente, das teorias da Gestalt e dos conceitos que fundamentam duas áreas do design de sinalização: o wayfinding, que se utiliza de recursos da sinalização para orientar e auxiliar os usuários a chegarem a um determinado destino, e a señalética cuja finalidade é a informação inequívoca e adaptada ao ambiente, bem como da linguagem visual e da tipografia, campos multidisciplinares que possam fornecer conteúdo para a realização do projeto.

Serão utilizadas metodologias na área da sinalização, apoiada por uma pesquisa de campo de cunho quantitativo com os frequentadores do campus com a finalidade de levantar informações que auxiliem na determinação do problema e na fundamentação do projeto. Utilizar-se-ão recursos fotográficos, plantas do local, anotações, identificação de fluxos de entrada e de saída, aspectos ambientais, condições de luminosidade, na coleta de dados e aplicações gráficas para a construção e representação do projeto final. O objetivo final é a execução de um produto que atenda de forma eficaz a demanda por informação e orientação dos usuários e que se torne parte integrante do campus.

A vida em comunidade exige da sociedade a ordenação de meios eficazes para a locomoção dos indivíduos nas cidades e em seus ambientes específicos. A qualidade da informação é essencial para que esse deslocamento aconteça de forma natural e dinâmica, sem a perda de tempo em seu trajeto.

Reforçada pela importante necessidade de comunicação para a mobilidade das pessoas, este estudo busca propor uma solução ao problema enfrentado principalmente pelos alunos do campus Dunas, que é o de localizar-se dentro e ao redor desta estrutura. Essa referida necessidade de comunicação inequívoca no ambiente construído da faculdade torna-se também a razão para o desenvolvimento deste trabalho.

Outro fator importante nesse trabalho é o da educação visual proporcionada pelo designer à comunidade, aplicando na sinalização atributos adequados à ergonomia informacional, ofertando ao frequentador destes espaços uma informação segura, imediata e confiável. 


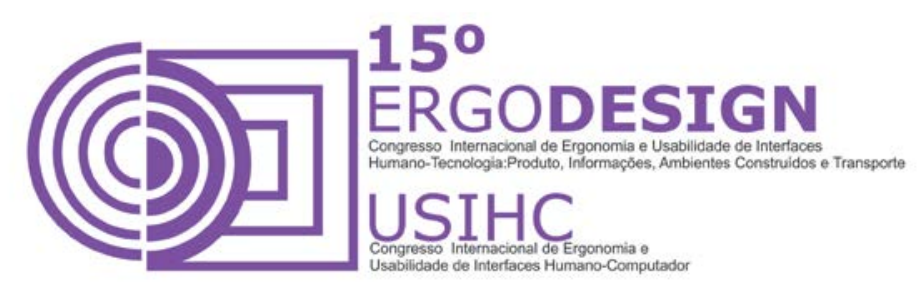

\section{O DESIGN DE INFORMAÇÃO}

Desde o princípio da história humana, a civilização já demonstrava meios de transmitir mensagens além das formas verbais. O estudo do homem sobre essas civilizações antigas com os seus próprios códigos e sem vínculo algum, mostra-nos algo comum a toda a raça humana, a necessidade de se comunicar. "Os egípcios, cerca de 3000 anos antes de Cristo, representavam aspectos de sua cultura por meio de desenhos e gravuras colocadas nas casas, edifícios e câmaras mortuárias". (BORDENAVE, 1997)

A comunicação é um ato comum aos indivíduos para se transmitir uma mensagem a um receptor por meio de um canal e se fazer entender e compreender o outro. Muitos são os meios pelo qual esse diálogo se estabelece. Pode-se vê-la, ouví-la e sentí-la. As reações das pessoas às várias mensagens em que se deparam durante o dia dependem primeiramente dos aspectos que tornam possíveis o entendimento do que se transmite, ou seja, sua qualidade.

Além dos fatores externos ligados ao ambiente, existem também barreiras particulares a cada indivíduo que interferem nesta compreensão, estes filtros são: "o caráter sensorial", como um problema de visão, por exemplo, "as características psicofisiológicas constitutivas do receptor", que podem ser a diferença de compreensão entre uma criança e um idoso e por fim o repertório ou "universo cultural" de cada um, a exemplo de uma gíria popular (MUNARI, 2001). Assim, pode-se afirmar que nossa interpretação ou resposta sobre qualquer mensagem está restrita a estes filtros externos e internos, independente qual seja a fonte e o canal.

Portanto, é importante notar que as pessoas são imbuídas fisicamente de ferramentas para a comunicação muito além da linguagem verbal da qual fazemos uso para falar e escrever. Essa linguagem não-verbal compreende uma rede intrincada e plural de sentidos e significados captados por nossa visão, tato, olfato e paladar.

\subsection{Sinalização, Señalética e Wayfinding}

Por sinalização, entende-se um sistema de comunicação para o controle do fluxo de pessoas e veículos, sendo determinante de condutas e desenvolvido de forma universal. Seja representando uma indicação, uma ordem, uma advertência, uma proibição ou uma instrução, seu objetivo não é apenas comunicar mas, sobretudo produzir uma reação imediata no observador (FRUTIGER, 2001). Muitos são os recursos que ela utiliza, como setas, mapas, letreiros, guias e vários outros com o objetivo de informar de modo seguro e rápido.

Os símbolos gráficos atribuem significado às informações transmitidas pelos sinais. A transmissão intencional dada pela mensagem passa a ser sua principal função. Na busca de uma melhor compreensão sobre o assunto, D'Agostini (2010) citando Costa (2007), acredita que para se entender um projeto de sinalização é necessário o equacionamento das variáveis de três grandes áreas de atividade: arquitetura, engenharia e desenho industrial através das competências do design de produto e do design gráfico. (COSTA (2007) apud D'AGOSTINI, 2010). Sinalização é atividade complexa. Variáveis como o tamanho da estrutura e a abrangência da necessidade, podem determinar o alto nível ou mesmo a simplicidade de um sistema.

Verifica-se aqui, o quão complexo pode ser um projeto de sinalização. Variáveis como o tamanho da estrutura e a abrangência da necessidade, podem determinar o alto nível ou mesmo a simplicidade do sistema. 


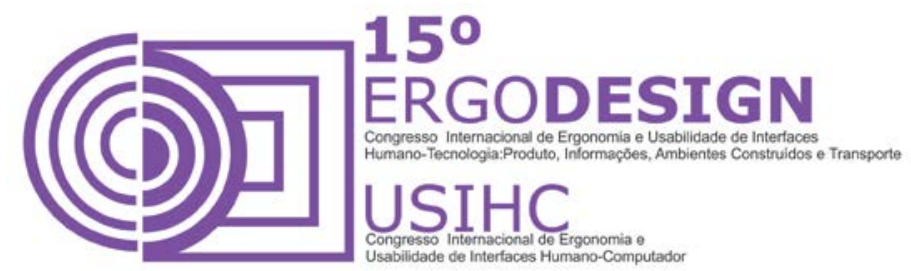

A Señalética, diferente da sinalização que impõe a informação ao usuário, oferta um sistema de comunicação visual totalmente adaptado e em harmonia com o ambiente em que atua. $\mathrm{O}$ autor Joan Costa (1989), afirma que a señalética "colabora com a engenharia da organização, a arquitetura, o ambiente e a ergonomia, sob o vetor do design gráfico, considerado em sua vertente mais utilitária de comunicação visual". Ainda segundo o autor, "o sistema de mensagens señaléticos não se impõe, não pretende persuadir, convencer, induzir ou influir nas decisões de ações dos indivíduos" (COSTA, 1989).

Assim, esse sistema comunica-se com usuário de forma livre, para que cada um se oriente conforme suas motivações, interesses e necessidades particulares. A Señalética também age em conjunto com a identidade visual, trabalhando como reforço a presença da marca em um ambiente, através de aspectos de estilo e padrões cromáticos da mesma.

Com relação ao Wayfinding, trata-se de um sistema de sinalização que baseia-se no processo de orientação espacial. O conceito moderno para a forma de sinalizar projetado ao movimento orientado surge nos anos 70, com os canadenses Romedi Passini (1992), arquiteto e psicólogo (environmental psychologist) e pelo designer autodidata Paul Arthur (1992) (GIBSON 2009). Partindo de estudos dos processos cognitivos dos indivíduos no momento da tomada de decisão, Passini e Arthur descobriram que, para entender como as pessoas encontram seus caminhos, primeiro precisam entender o processo adjacente, sua localização. As pessoas que se encontram em ambientes desconhecidos precisam saber onde realmente estão no complexo e a localização de seu destino, a fim de formular seus planos de ação.

São princípios básicos de acordo com os autores:

O planejamento espacial (ordenação das informações na tomada de decisão) e a comunicação (percepção espacial, circulação, fluxos, marcos, a informação) são, na opinião destes autores, os princípios básicos do wayfinding design, sendo assim também considerados neste trabalho.

\subsection{Gestalt e cognição espacial}

Entendida como "boa forma", a Gestalt é uma teoria baseada em estudos da psicologia experimental, que articula categorias e conceitos sobre o significado da forma e sua leitura. É a área da Psicologia que procura explicar a relação sujeito-objeto no campo da percepção, opondo-se às ideias subjetivas de que tudo que vemos, no julgamento de belo e feio, é relativo. "[...] o importante é perceber a forma por ela mesma; vê-la como "todos" estruturados, resultado de relações. Deixar de lado qualquer preocupação cultural e ir à procura de uma ordem, dentro do todo". (KEPES (1966) apud GOMES FILHO, 2000)

Diversas são as categorias e conceitos que abrangem diferentes situações para a leitura visual da forma, esta apresentada de modo isolado ou como um todo. Para este trabalho do projeto de sinalização do Campus Dunas da Fanor, serão utilizados, apenas aqueles considerados mais importantes, a saber:

- Forma: a aparência do produto;

- Pregnância da forma: rápida assimilação;

- Contraste: fundo e figura;

- Equilíbrio: relações simétricas quanto possível;

- Harmonia: produto aplicado como parte do meio; 


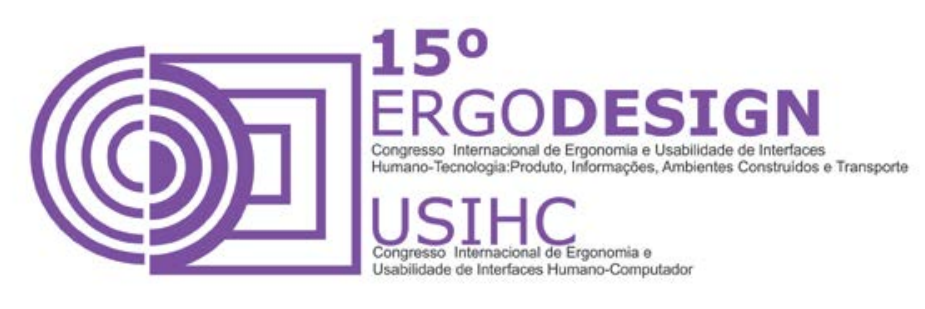

- Clareza: compreensão imediata da forma.

\subsection{Elementos gráficos da sinalização}

Os elementos gráficos da sinalização considerados neste trabalho envolvem aspectos importantes para a comunicação visual, são eles: a semiótica, a tipografia, os critérios de legibilidade e o cromatismo.

A semiótica é a ciência dos signos e todas as linguagens e acontecimentos culturais como se fossem fenômenos produtores de significado, neste sentido define a semiose. Em outras palavras, é a ciência que estuda todas as formas do homem se comunicar, abrangendo as linguagens verbais e não-verbais, oral, escrita, gestual, corporal, desenhada, representada etc. Seu estudo dessa área do conhecimento auxilia na compreensão de todos o fenômenos que presentes entorno das pessoas e revela as formas como o indivíduo dá significado a tudo que o cerca. (D'AGOSTINI, 2010)

Em relação aos conceitos que integram a semiótica peirceana (de Charles Sanders Peirce) segundo Niemeyer (2009), o signo é uma manifestação que representa algo que lhe deu origem. Ele só pode funcionar como signo se carregar esse poder de representar, substituir um outro diferente dele. Na lógica peirceana o signo representa uma relação triádica e essa tricotomia se compõe pelo "Signo em si ou Representâmen", pelo "Objeto" e pelo "Interpretante". Na sinalização o objeto resultante ofertado por quem a projeta "é tratado como portador de representações, participante de um processo de comunicação" (NIEMEYER, 2009). Por isto, é pertinente ao designer compreender os processos semióticos aplicados ao produto, para assim, ofertar uma solução eficiente ao problema de orientação e informação do público.

Essencial na sinalização, a tipografia empregada no projeto juntamente com a pictografia e o cromatismo, torna-se um dos fatores mais importantes para sua funcionalidade. A tipografia é a arte e o processo de criação na composição de um texto, físico ou digital. Assim como no design gráfico em geral, o objetivo principal da tipografia é dar ordem estrutural e forma à comunicação impressa. A correta utilização de seu tamanho e largura combinada às distâncias necessárias à sua leitura, aspectos estes estudados na ergonomia informacional, fornecem uma rápida assimilação da informação pelo usuário. A escolha da família tipográfica para este trabalho foi eleita por apresentar atributos de legibilidade, leiturabilidade e pregnância.

Vital para sistemas de sinalização, a legibilidade é a qualidade que determina a facilidade de leitura de alguma coisa. No contexto da informação visual depende da iluminação do ambiente, do contraste e da pureza da cor. Na sinalização visual segundo a NBR9050(2004), "informações visuais devem seguir premissas de textura, dimensionamento e contraste de cor dos textos e das figuras para que sejam perceptíveis por pessoas de baixa visão" (p.22). Itiro lida(2005), recomenda aplicar os princípios de legibilidade na tipografia utilizada no que chama de dispositivos de informação (que enquadra também a sinalização). O autor desenvolveu um processo para aplicação de textos escritos em projetos de sinalização:

i. Usar tipos de letras simples;

ii. As dimensões das letras dependem da distância visual. Como regra geral, a altura das letras maiúsculas deve ser de 1/200 de distância; 


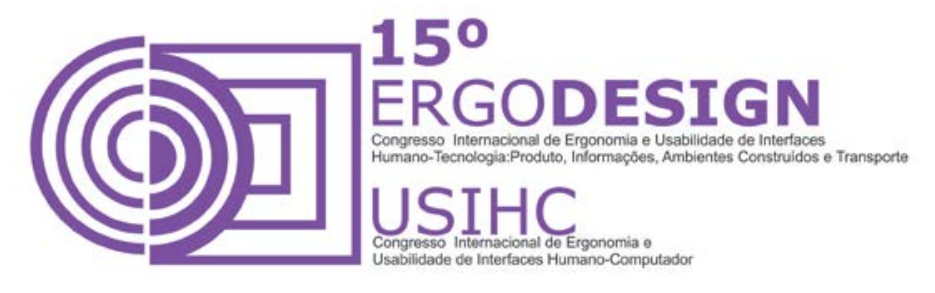

iii. Usar letras maiúsculas apenas no início da frase ou em nomes e títulos;

iv. Deve haver proporcionalidade entre a largura e a altura das letras;

v. O espaçamento entre linhas deve ser proporcional ao seu comprimento;

vi. Assegure um bom contraste figura/fundo.

A função cor para a comunicação visual é talvez um dos fatores mais importantes. É o cromatismo que está presente em todo o alcance do nosso campo visual tanto na natureza quanto de forma artificial. Quando usada de forma coerente, pode transmitir significados, delimitar a forma e destacar objetos no ambiente. "As cores são o suporte óptico do discurso da sinalização e é a primeira sensação óptica que se recebe em um ambiente". (COSTA (2007) apud D’Agostini, 2010, p.36)

Assim como outros atributos para o projeto mencionados anteriormente, o uso das cores aplicadas ao projeto do Campus Dunas tem como propósito reforçar a imagem da marca da instituição, enfatizando a continuidade e a coerência do sistema visual.

\section{O PROJETO DE SINALIZAÇÃO DO CAMPUS DUNAS}

Em projetos de sinalização, o desenvolvimento de sistemas complexos eficientes só é possível se puderem ser gerenciados, pois muitos projetos funcionam com a interação de uma equipe multidisciplinar que trabalha seguindo um controle para as tarefas requisitadas do projeto. Essa organização é feita pela adoção de procedimentos metodológicos que dão fluxo ao andamento do trabalho. A importância da adoção de uma metodologia para o desenvolvimento de produtos pela fixação de metas só é útil se for acompanhada dos procedimentos para verificar se essas metas serão atingidas. (BAXTER, 2011)

\subsection{Metodologia projetual}

Projetos de sinalização tendem a apresentar necessidades de solução bastantes particulares. $\mathrm{Na}$ aplicação de uma metodologia, alguma adaptação faz-se necessária devido ao seu tipo e tamanho, em projetos menores algumas etapas são, por vezes, combinadas ou mesmo eliminadas (GIBSON, 2009). A metodologia aplicada para o desenvolvimento do sistema de wayfinding para o campus Dunas foi a desenvolvida por David Gibson (2009) descrita em seu livro The Wayfinding Handbook que aborda três grandes etapas do projeto de sinalização podendo ser subdivididas em fases descritas na Figura 1. 

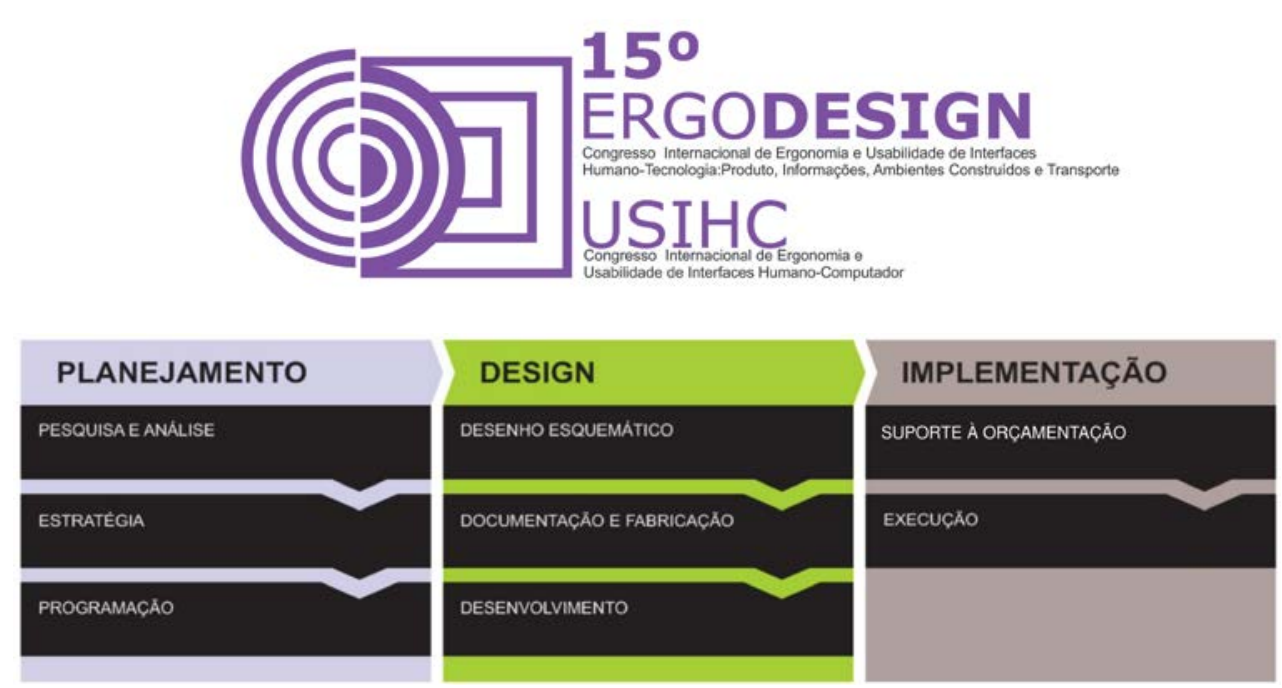

Figura 1 - Metodologia de Gibson, subdividida em etapas. Fonte: Adaptado de Gibson (2009).

O esquema metodológico de Gibson (2009) serve como parâmetro projetual para este projeto, entretanto, algumas etapas ligadas ao detalhamento executivo e implementação não foram consideradas por não fazerem parte dos objetivos deste trabalho. De acordo com este autor, para que um projeto de wayfinding seja bem sucedido, há que se considerar seriamente três variáveis: 1) compreensão da natureza da organização do cliente, o tipo de negócio em que atua; 2) as pessoas com as quais a organização se comunica, seu público; 3) o tipo de ambiente em que o sistema será instalado. Estes elementos são essenciais, pois auxiliam no estudo dos fluxos de pessoas e determina os locais passíveis de maior circulação.

A vista aérea do Campus Dunas, no ano de 2013, pode ser visualizada na Figura 2, retirada com o auxílio do Google Earth, quando este projeto estava sendo executado. No desenvolvimento das propostas, foram utilizadas as plantas baixas fornecidas pela da instituição, mas que não contemplavam a realidade da estrutura por conta das inúmeras interferências sofridas por reformas constantes.

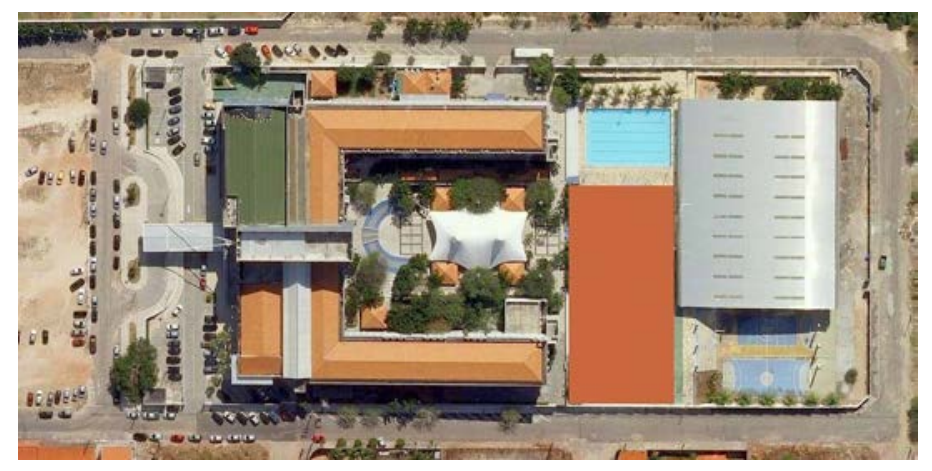

Figura 2 - Vista aérea do Campus Dunas. Fonte:

Adaptado do Google Earth (2014).

\subsection{Pesquisa de campo, público e estudo de rotas}

Em outubro de 2013, a pesquisa de campo consultou 35 frequentadores do campus, submetidos a um questionários com 08 itens a respeito da locomoção na faculdade. Dos participantes frequentadores, $100 \%$ concordaram que a sinalização existente no campus 


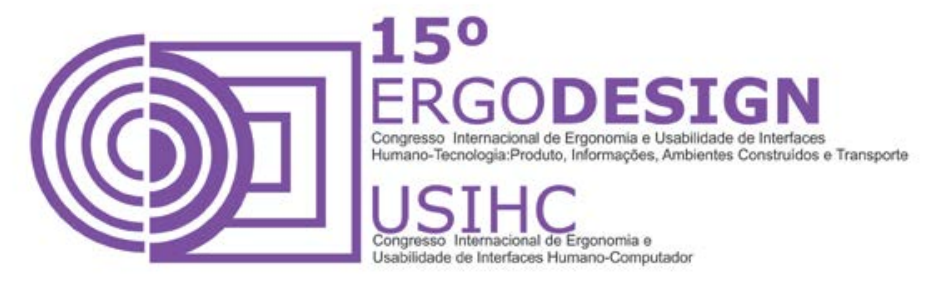

poderia melhorar se alguns elementos como totens, placas e mapas fossem utilizados para indicar e identificar seus destinos.

Para coleta dos dados, foi adotada a pesquisa de campo. Através da observação de fatos e fenômenos à medida que ocorriam, "espontaneamente, na coleta de dados a eles referentes e no registro de variáveis" que se supunham relevantes, para serem analisados em momento posterior (LAKATOS; MARCONI, 2003). De acordo com dados obtidos pelo Departamento de Marketing da faculdade, na Fanor/DeVry, o público é formado, principalmente, por pessoas de 18 a 40 anos, de ambos os sexos. São homens e mulheres alfabetizados, estudantes, professores, funcionários e visitantes que são a maioria classe média e alta, com poucas exceções. Em estudos realizados nas primeiras etapas de coleta de informações, durante a observação dos espaços e do comportamento dos frequentadores do campus, foi possível determinar o registro dos pontos carentes de sinalização informativa como também de sinalização direcional, obtendo-se a seguinte classificação das características do ambiente:

- Tipo de ambiente: espaço público de livre acesso;

- Quilo Habitat: ambiente que se pode registrar o fluxo de milhares de pessoas por dia;

- Natureza: ambiente misto, com espaços abertos e fechados;

- Característica temporal: ambiente permanente;

- Utilização do espaço: ambiente de circulação, trânsito constante de pessoas;

- Característica construtiva: subtérreo, térreo, $1^{\circ}$.- $4^{\circ}$. andar;

- Arquitetura: moderna;

- Números de acessos: suficiente;

- Tipos de acessos: em veículos e a pé.

As informações geradas nesta fase de desenvolvimento obtidas pelo estudo do perfil do público e sua opinião, a análise dos problemas, o estudos de rotas e as características do ambiente, os estudos dos autores como referência metodológica, reforçada pela metodologia projetual adotada deram suporte para os requisitos que determinam a linha de ação para o projeto. Outra fonte de informação muito útil foi obtida pela Análise de Similares, onde se visitou espaços com grande circulação de pessoas na mesma cidade, como o Shopping Iguatemi, a Loja Etna e na serra gaúcha em Gramado, o Hotel Gramado Master Palace.

\section{PROPOSTA PARA O NOVO SISTEMA DE SINALIZAÇÃO}

Após a coleta de dados, optou-se por fazer a proposta de um sistema de wayfinding que priorizasse o equilíbrio de seus elementos em harmonia com uma composição formal moderna, de fácil leitura e em consonância com o ambiente sinalizado, reforçando a identidade visual da instituição. É composto por dois tipos principais de sinalização: direcional e informativa.

Os materiais eleitos foram selecionados com base na durabilidade, versatilidade e qualidade de acabamento, bem como na predominância mercadológicoa para projetos similares. 


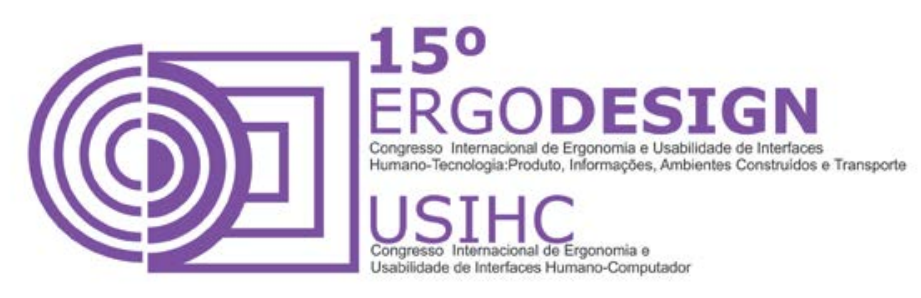

A família tipográfica selecionada é a Frutiger LT 55 Roman (negrito e normal) para texto primário e Frutiger CE 45 Light (leve-itálico) para texto secundário.

Os pictogramas desenvolvidos para o projeto, bem com as setas obedecem aos padrões internacionais de sinalização, embora alguns tenham sido personalizados e redesenhados.

O padrão cromático utilizado foi obtido das cores institucionais descritas no manual da marca DeVry University, parceiro internacional da Fanor no Brasil. As cores obtidas desempenharam a função de setorizar o ambiente da faculdade dividindo-a em quarto características: Área Acadêmica, Serviços e Acessos, Atendimento e Parque Esportivo utilizando-se respectivamente de duas cores primárias e duas secundárias. Desta maneira, a cor pode ajudar na definição de um mapa cognitivo, marcando diferentes ambientes do campus.

A alternativa apresentada busca uma linguagem familiar na semelhança de suas formas, com o apoio do padrão cromático e seus materiais para sustentar sua configuração formal conjunta.

O totem para o mapa do campus é o principal elemento do sistema e deve estar localizado nas entradas principais de maior fluxo da faculdade. Através do mapa do ambiente físico firma-se o propósito de auxilio do usuário na criação de mapas mentais para o deslocamento eficiente.

\subsection{Detalhamento técnico, proporção e maquete 3D}

Partindo da alternativa eleita para a configuração formal das placas do projeto, a Figura 3 apresenta os detalhes técnicos de cada peça que compõem o sistema desenvolvido, compreendendo medidas, posicionamento espacial com base na antropometria da escala humana considerando um homem de 1,70m. Por fim apresenta-se a representação artística através de maquete 3D.

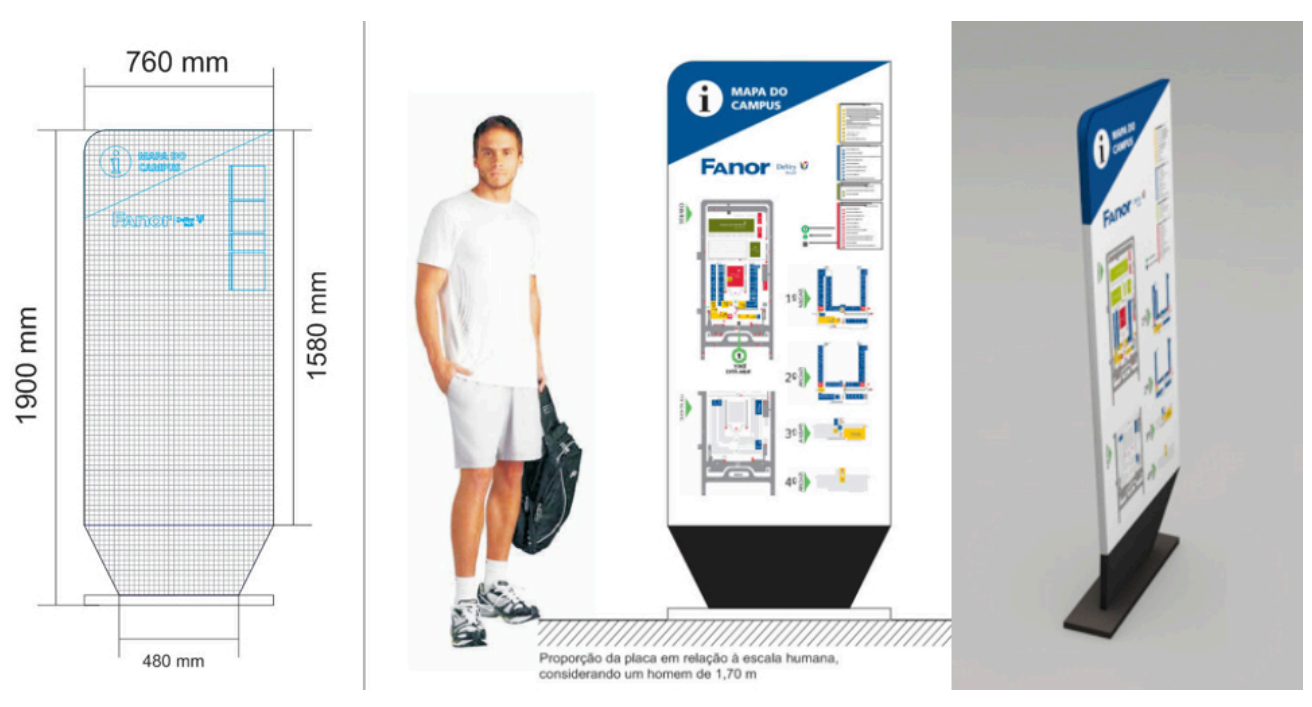

Figura 3 - Placa tipo A: desenho técnico, proporção e maquete 3D. Fonte: Acervo pessoal. 


\subsubsection{Elementos do sistema}

Para compor a família do sistema de placas foram desenvolvidos oito elementos (Figura 4) que buscam atender as necessidades de orientação e informação do ambiente.

Por sua característica coerente com a senalética do lugar, podem se estender para outras variações conforme forem surgindo a demanda pela ampliação ou reforma do espaço construído desde que mantidos o padrão gráfico e cromático das peças criadas.

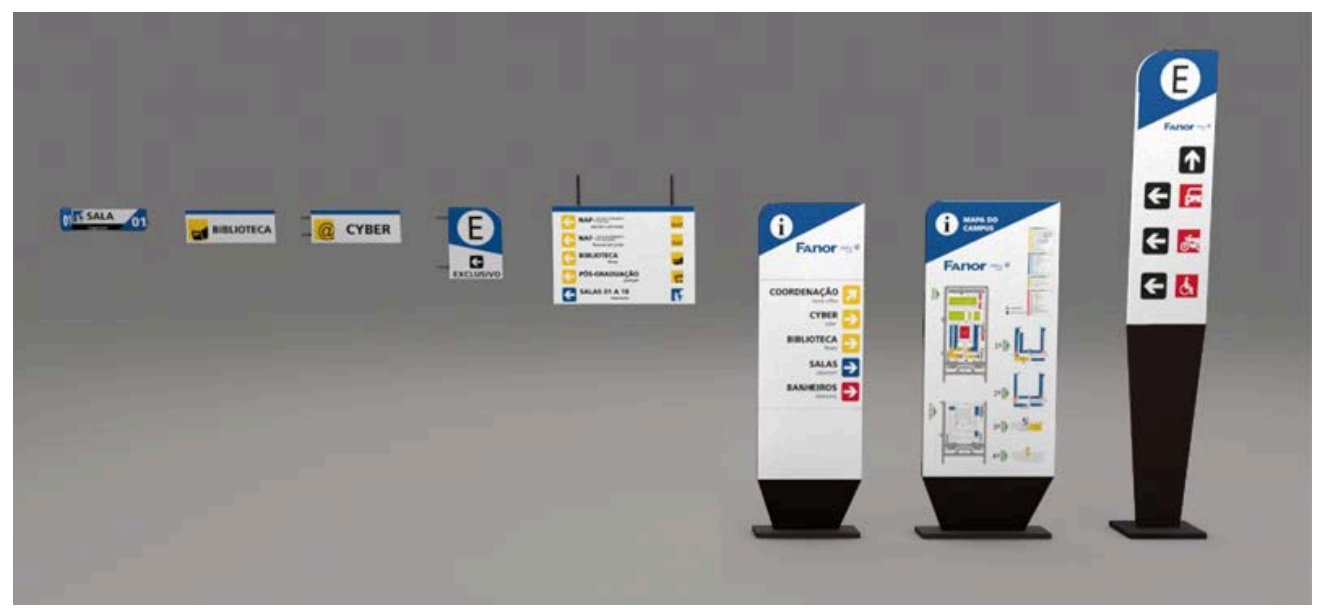

Figura 4 - Família de placas do sistema de wayfinding. Fonte: Acervo pessoal (2014).

\subsubsection{Especificações}

A Tabela 1 abaixo apresenta as especificações técnicas para o sistema desenvolvido com detalhamento para os materiais, tipos e pictogramas, fixação e dimensões das pecas e bases, em milímetors. 


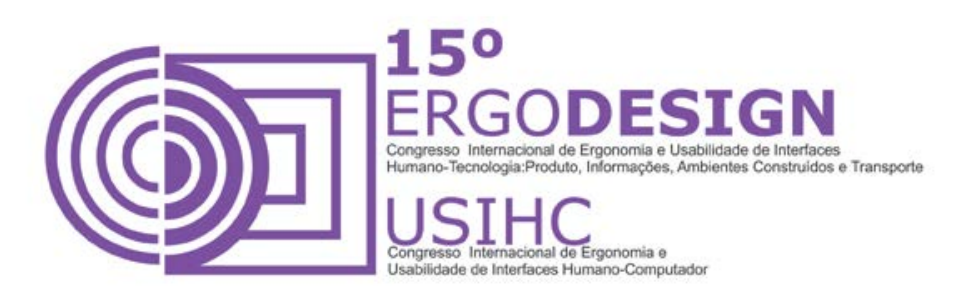

\begin{tabular}{|c|c|c|c|c|c|}
\hline ELEMENTOS & NOMECLATURA & MATERIAIS & $\begin{array}{c}\text { TIPOSE } \\
\text { PICTOGRAMAS }\end{array}$ & FIXAÇĀOO & $\begin{array}{l}\text { DIMENSÕES } \\
\text { Peça e Base } \\
\text { (MM) }\end{array}$ \\
\hline IIPOA & Totem do mapa & $\begin{array}{c}\text { PVC e base em aço } \\
\text { galvanizado }\end{array}$ & Pintura automotiva & Parafusos e buchas & $\begin{array}{r}1900 \times 760 \times 30 / \\
760 \times 325 \times 30\end{array}$ \\
\hline ТІРО B & Totem direcional & $\begin{array}{l}\text { PVCe base em aço } \\
\text { galvanizado }\end{array}$ & Pintura automotiva & Parafusos e buchas & $\begin{array}{r}1900 \times 600 \times 30 / \\
600 \times 325 \times 30\end{array}$ \\
\hline TIPOC & Identificaşäo salas & $\begin{array}{l}\text { MDF revestido com } \\
\text { PVC }\end{array}$ & Vinil adesivado $3 \mathrm{M}$ & $\begin{array}{c}\text { Chapa de ferro } \\
2 \mathrm{~mm} \text {, parafusose } \\
\text { buchas }\end{array}$ & $\begin{array}{r}120 \times 420 \times 30 / \\
120 \times 120 \times 30\end{array}$ \\
\hline TIPOD & Identificaçäo frontal & $\begin{array}{l}\text { MDF revestido com } \\
\text { PVC }\end{array}$ & Vinil adesivado $3 \mathrm{M}$ & Fita Vнв зм & $180 \times 500 \times 30$ \\
\hline TIPOE & Identificasăo projetada & $\begin{array}{l}\text { MDF revestido com } \\
\text { PVC e tubos } 30 \mathrm{~mm} \\
\text { em aluminio }\end{array}$ & Vinil adesivado $3 \mathrm{M}$ & Parafusos e buchas & $180 \times 500 \times 30$ \\
\hline TIPOF & Direcional ačrea & $\begin{array}{l}\text { MDF revestido com } \\
\text { PVC e tubos } 30 \mathrm{~mm} \\
\text { em aluminio }\end{array}$ & Vinil adesivado $3 \mathrm{M}$ & Parafusos e buchas & $550 \times 800 \times 30$ \\
\hline TIPOG & Estacionamento totem & $\begin{array}{l}\text { PVC e base em aço } \\
\text { galvanizado }\end{array}$ & Pintura automotiva & Parafusos e buchas & $\begin{array}{l}2801 \times 450 \times 40 / \\
450 \times 325 \times 30\end{array}$ \\
\hline Трон & Estacionamento aérea & $\begin{array}{c}\text { PVC e tubos } 30 \mathrm{~mm} \mathrm{em} \\
\text { aluminio }\end{array}$ & Pintura automotiva & Parafusose e buchas & $401 \times 300 \times 30$ \\
\hline
\end{tabular}

\subsubsection{Proposta de aplicação}

Os locais ofertados para se inserir os elementos do sistema foram escolhidos com base no estudo de rotas de pedestres e veículos que definem todos os marcos onde ocorrem a tomada de decisão do público frequentador do campus. A Figura 5 permite ter uma visualização aproximada do ambiente natural em que se propõe aplicar alguns dos itens mais importantes para o sistema de wayfinding, que vai permitir uma identificação imediata dos acessos, definindo rotas e permitindo ao usuário a rápida tomada de decisão.

As três fotografias que compõem esta imagem, mostram locais de acesso na entrada no prédio, que atualmente não possuem nenhum tipo de informação.
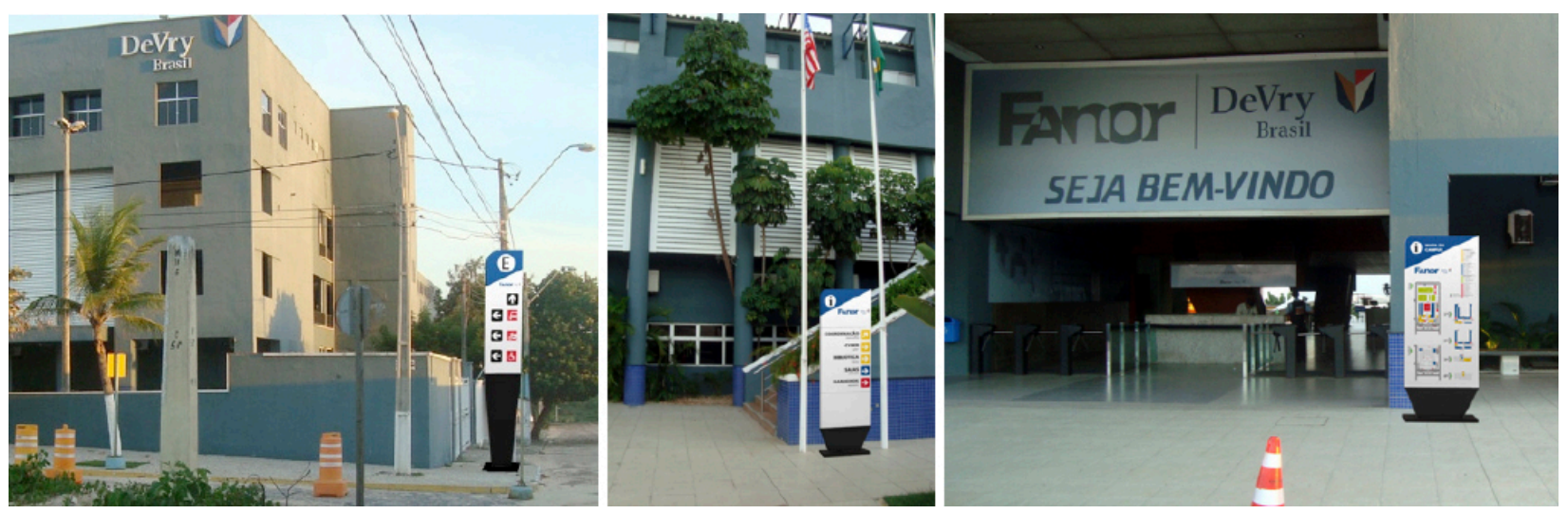

Figura 5 - Simulação de aplicação do sistema de sinalização. Fonte: Acervo pessoal (2014). 


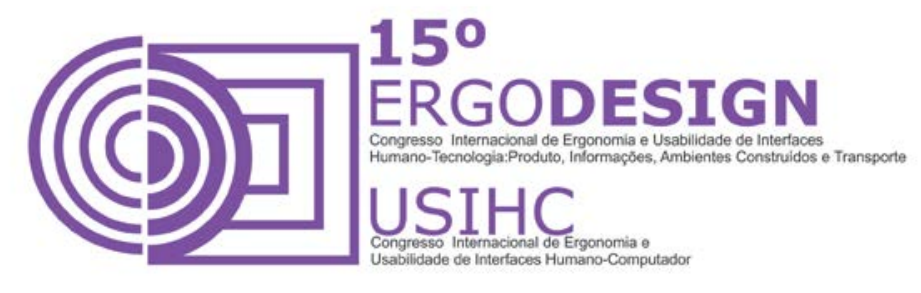

\section{CONSIDERAÇÕES FINAIS}

O campus Dunas da Fanor/DeVry possui um resquício de uma tentativa de sinalizar o ambiente interno. É defasado, incoerente e totalmente sem uso depois de tantas reformas na sua estrutura e também pela ausência de elementos que deveriam existir no projeto original. Estes aspectos, observados no decorrer deste trabalho, deram margem para a oferta de um sistema de wayfinding no espaço do campus. As possibilidades para a implantação mostraram-se coerentes à medida em que se conhecia o espaço, público e dificuldades de informação e orientação. O levantamento destes dados e as pesquisas relacionadas ao tema foram fundamentais para o resultado desenvolvido e mostraram que $100 \%$ de seus frequentadores enfrentam algum tipo de dificuldade no deslocamento neste ambiente.

A metodologia aplicada ao projeto de sinalização referenciada por Gibson mostrou-se uma importante ferramenta para execução das etapas deste sistema, como também o conteúdo de D'Agostini que trouxe a tona o entendimento mais aprofundado sobre o campo da sinalização.

A família de elementos ofertados neste projeto de wayfinding ficou dentro das expectativas. Sua quantidade, os tipos de peças concebidos e os materiais visam atender ao tipo de situação característica de cada ambiente a ser sinalizado e possíveis novas situações. Entretanto, devido ao estado atual do campus que passa por uma ampliação com a construção de um novo bloco, não é possível prever a organização final após o fim da obra. O uso de um padrão cromático baseado nas cores da instituição reforça a identificação da marca com seu público e auxilia a divisão de setores no ambiente como um guia para a visualização mais rápida na busca por informação e orientação na faculdade.

O projeto aqui apresentado necessita da elaboração de um manual de sinalização caso haja intenção de implantação por parte da instituição. Sobre este aspecto é preciso revisar o sistema de informação nele contido com base na situação atual que o campus venha a apresentar.

Funcionários e estudantes veteranos, após passarem pela traumática experiência de entrar no ambiente caótico e sem indicação de rotas, já desenvolveram seus próprios sistemas de rotas individuais para ir e vir diários e rotineiros. Os que mais são impactados são os visitantes e novatos. E é pensando neles que este sistema pode oferecer melhorias definitivas.

\section{REFERÊNCIAS}

ARTHUR, P.; PASSINI, R. Wayfinding People, Signs, and Architecture. New York: McGraw-Hill, 1992.

BAXTER, Mike. Projeto de Produto: Guia Prático para o Design de Novos Produtos. São Paulo: Edgard Blücher, 2011.

BORDENAVE, Juan. O que é comunicação. São Paulo: Brasiliense, 1997.

COSTA, Joan, Señalética: De la siñalización al diseño de programas. 2a edição., Barcelona, 2 A, 1989.

D'AGOSTINI, Douglas. Design de sinalização: planejamento, projeto \& desenho. Porto Alegre: Editora UniRitter, 2010.

FRUTIGER, Adrian, Sinais e Símbolos - Desenho, Projeto e Significado. São Paulo: Martins Fontes, 2001. 


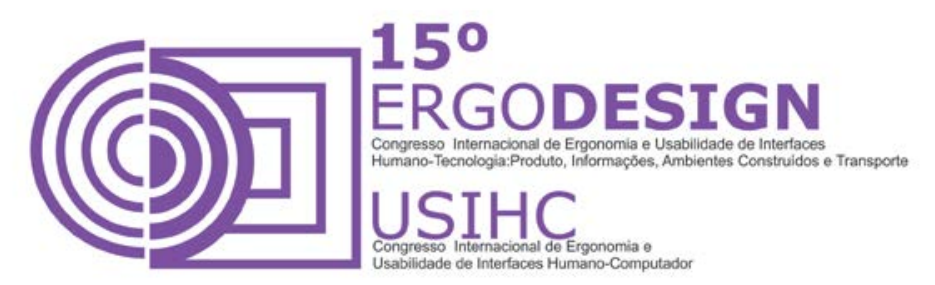

GIBSON, David, The Wayfinding Handbook - Information design for public places. New York: Princeton Architectural Press, 2009

GOMES FILHO, João. Gestalt do objeto: sistema de leitura visual da forma. São Paulo: Escrituras editora Ltda, 2004.

IIDA, Itiro. Ergonomia: produto e produção. São Paulo: Editora Edgard Blücher Ltda, 1990.

LAKATOS, Eva Maria; MARCONI, Marina de Andrade. Fundamentos de metodologia científica. $5^{\mathrm{a}}$ ed. São Paulo: Atlas, 2003.

MUNARI, Bruno. Design e comunicação visual. São Paulo: Martins Fontes, 2001.

NIEMEYER, Lucy. Elementos de semiótica aplicados ao design. Rio de Janeiro: 2AB, 2009.

ASSOCIAÇÃO BRASILEIRA DE NORMAS TÉCNICAS. Acessibilidade a edificações, mobiliário, espaços e equipamentos urbanos: NBR 9050. Rio de Janeiro, 2004. 